\title{
Risk perception and knowledge of hepatitis B infection among cleaners in a tertiary hospital in Nigeria: A cross-sectional study
}

\author{
Olumide Abiodun ${ }^{\mathrm{a}, *}$, Olusola Shobowale ${ }^{\mathrm{b}}$, Charles Elikwu ${ }^{\mathrm{b}}$, Daniel Ogbaroc, \\ Adebola Omotosho ${ }^{\mathrm{d}}$, Beatrice Mark ${ }^{\mathrm{d}}$, Akinyemi Akinbola ${ }^{\mathrm{d}}$ \\ a Department of Community Medicine, Benjamin Carson School of Medicine, Babcock University, Ilishan-Remo, Ogun State, Nigeria \\ ${ }^{\mathrm{b}}$ Department of Medical Microbiology and Parasitology, Benjamin Carson School of Medicine, Babcock University, Ilishan-Remo, Ogun State, Nigeria \\ ${ }^{\mathrm{c}}$ Department of Hematology and Blood Transfusion, Benjamin Carson School of Medicine, Babcock University, Ilishan-Remo, Ogun State, Nigeria \\ d Department of Community Medicine, Babcock University Teaching Hospital, Ilishan-Remo, Ogun State, Nigeria
}

\section{A R T I C L E I N F O}

\section{Article history:}

Received 8 November 2017

Accepted 5 December 2017

Available online 6 December 2017

\section{Keywords:}

Healthcare workers

Hepatitis B infection

Hepatitis B vaccine

Cleaners

Risk perception

\begin{abstract}
A B S T R A C T
Background: Hepatitis B infection is a leading pathogenic infection that constitutes occupational hazard to health care workers. The current study examines the knowledge of hepatitis B infection and hepatitis B vaccination and uptake of the vaccine among the cleaners in a tertiary hospital in Nigeria.

Materials and methods: A cross-sectional hospital-based study of 89 cleaners using a standardized interviewer-administered questionnaire for data collection was conducted. Data were analyzed with SPSS version 21 software.

Results: Among the participants, 12 (13.5\%), 12 (13.5\%) and 19 (21.3\%) had low, medium and high-risk perception of acquiring hepatitis B infection respectively. Awareness of hepatitis B infection was low (65.2\%). The mean knowledge scores concerning hepatitis B infection (4.24 out of 26) and hepatitis B vaccine ( 1.06 out of 26 ) were low. Twenty-five $(28.1 \%)$ of the participants had ever had screening while none of them reported being vaccinated against hepatitis $B$.

Conclusions: Hospital cleaners have poor risk perception, low level of awareness and poor knowledge about hepatitis B infection. Health workers might differ in what they know about hepatitis B infection and vaccine because of the differences in the levels of education, training, and perceived relevance within hospital settings.
\end{abstract}

(c) 2017 Published by Elsevier, a division of RELX India, Pvt. Ltd on behalf of INDIACLEN.

\section{Introduction}

Hepatitis B infection is a viral infection caused by the hepatitis B virus (HBV). The $\mathrm{HBV}$ is transmitted through mucosal or percutaneous contact with infected blood and other body fluids, particularly semen and vaginal fluid. Hepatits B infection is one of the leading bloodborne pathogenic infections that constitute an occupational hazard to health care workers (HCWs). ${ }^{1}$ It is an infection that runs a chronic course, and in 15 to $40 \%$ of cases, it may lead to chronic liver diseases, liver failure, hepatocellular carcinoma and death. ${ }^{2}$ Hepatitis B infection may also cause the deposition of immune complexes, especially in the kidney. It has a chronic carrier status resulting in inactive HBV carriers being able to transmit the virus. ${ }^{3}$

Abbreviations: HBV, hepatitis B virus; HCW, health care workers; HBsAg, hepatitis B surface antigen; BUTH, Babcock University Teaching Hospital.

* Corresponding author.

E-mail address: olumiabiodun@gmail.com (O. Abiodun).
It is estimated that HBV accounts for 240 million chronic infections and more than 780,000 annual deaths due to chronic liver diseases globally. Most of the chronic carriers of HBV live in East Asia and sub-Saharan Africa where between 5 and $10 \%$ of the adult population are chronic carriers. ${ }^{1}$

There is a huge risk of contracting Hepatitis B infection in Nigeria because about $75 \%$ of the Nigerian adult population is at risk of exposure to the virus and between $9 \%$ and $39 \%$ have inactive HBsAg state, in spite of very low vaccination rates. ${ }^{4}$ Different reports have shown varying estimates of national and group specific HBsAg prevalence rates. The prevalence is between 10 and $15 \%$ in the general population; $25.7 \%$ among surgeons; $23.4 \%$ among voluntary blood donors and $16.3 \%$ among infants. ${ }^{5-8}$ It is the major risk factor for chronic liver diseases in Nigeria. In southern Nigeria, $58.1 \%$ of patients with chronic liver diseases were found to be positive for hepatitis B surface antigen (HBsAg). ${ }^{9}$ A systematic review of studies on hepatitis B infection in Nigeria between the year 2000 and 2013 gave a pooled prevalence of hepatitis B in Nigeria as $13.6 \%{ }^{10}$ 
Hepatitis B infection can be prevented by the practice of standard precautions which includes ensuring personal hygiene; the use of relevant personal protective equipment; and by the proper disposal of used sharps, and medical wastes in healthcare settings. The implementation of safe blood and safe sex strategies also protect against the infection. ${ }^{1}$ However, the mainstay of hepatitis B prevention is hepatitis B vaccination. Hepatitis B vaccine is safe, cost-effective, and gives protection for at least 20 years or for life. The vaccine is recommended for all children and high-risk individuals including health workers and other people whose occupation expose them to blood and blood products. ${ }^{1}$

Transmission of hepatitis $B$ infections occurs in healthcare settings through needle pricks and the reuse of needles and syringes. ${ }^{1}$ About $6 \%$ of the global populations of health care workers are exposed to hepatitis B virus. ${ }^{11}$ Studies carried out in South Africa, Sudan, Tanzania, and Morocco showed that health care workers had good knowledge about hepatitis B infection but poor knowledge and uptake of hepatitis B vaccination. ${ }^{11-15}$

Cleaners, like other hospital workers, have an additional risk of acquiring hepatitis B infection. They are exposed to blood and medical wastes. Unlike other hospital workers, they are usually less educated, have little or no formal training, and often have their specific infection control-related training needs overlooked within the healthcare setting. ${ }^{16}$ While many studies examining the knowledge of health workers about hepatitis B infection exist, there is a paucity, if any exist, of studies that concentrate on this group of health workers alone. We are not aware of any such study in Nigeria and sub-Saharan Africa.

The risk of contracting hepatitis $B$ infection remains persistently high in sub-Saharan Africa despite the availability of a safe and cost-effective vaccine. The current study examines the knowledge of hepatitis B infection and hepatitis B vaccination; and the uptake of the vaccine among the cleaners in a tertiary hospital in Nigeria.

\section{Materials and methods}

\subsection{Study design and setting}

This is a cross-sectional hospital-based study that was conducted between the 1st and 30th of June 2016 at the Babcock University Teaching Hospital (BUTH), Ilishan-Remo, Nigeria. BUTH is a 250-bed teaching hospital and referral center that serves 3 southwestern states in Nigeria with a combined population of about 23 million. The hospital had 98 Cleaners in its employment at the time of the study.

\subsection{Participants and samples}

The study was announced at the mandatory daily devotion for all employees of the hospital for five consecutive days. Participation was voluntary and the cleaners were free to decline or withdraw participation from the study at any time without any consequences. All cleaners who had been in the employment of the hospital for at least six months were eligible to take part in the study. Signed consent was obtained from each participant.

An interviewer-administered questionnaire was used to collect information on demographics, the risk of contracting hepatitis $\mathrm{B}$ infection (11 items), knowledge about hepatitis B infection (26 items) and vaccine (13 items), and the hepatitis B immunization status of the participants. The language of the interview was English which is well understood by the participants. Blood samples were also taken to evaluate the HBV status of the participants. The interviewers were conducted by trained research assistants. These assistants were nurses who received a 2-day training on infection control with emphasis on prevention and control of occupational exposure to HBV infection; and on the objectives and procedures of the research.

\subsection{Data management}

The completeness and consistency of the collected data were checked daily by the study supervisors before submission to the Lead investigator. All the data were entered by two data clerks independently. Data cleaning was done by the lead investigator by examining summary tables of the data. Only properly filled questionnaires were included in the analysis. Data was analyzed with SPSS version 21 software. Proportions, means, and standard deviations were derived and the data is presented with frequency tables. Scores of 0 and 1 were allocated to good and bad responses to the HBV infection risk assessment and to the wrong and correct knowledge items respectively. Total scores for each of the participants were derived. Perceived risk of hepatitis B infection was assessed by asking the participants to respond to the closedended question "How would you assess your risk of contracting hepatitis B infection?" They were thus categorized as low, moderate, or high risk perception groups. The participants were divided based on the assessment of their actual risk of hepatitis B infection into three groups. The first group; Low-risk group consisted of those whose risk scores were between 0 and 3 . The second group; moderate-risk group consisted of those whose risk scores were between 4 and 5 . Those with scores of 6 and above were regarded as high-risk. The participants were also categorized into three groups; 'poorly knowledgeable', 'fairly knowledgeable' and 'knowledgeable' about HBV infection based on knowledge scores of $<9,9-13$, and $>13$ respectively out of a maximum possible score of 26 . The participants were also determined to have 'poor', 'average' and 'good' knowledge about hepatitis B vaccine based on scores of $<5,5-7$, and $>7$ respectively out of a maximum possible score of 13 . Two infectious disease specialists reviewed the instrument and established content validity and suitability in the study context. Test-retest reliability was conducted to assess the stability of the instrument by estimating the intra-class correlation coefficient (ICC). Twenty cleaners from a tertiary hospital participants completed the questionnaire twice at two weeks interval. ICC values of 0.40 or above were considered satisfactory. The study instrument was then pretested among 20 cleaners in another tertiary hospital and necessary corrections were made.

\section{Results}

Eighty-nine of the ninety-eight cleaners in the employment of the BUTH fully participated in the study giving a response rate of $90.8 \%$.

\subsection{Socio-demographic characteristics of the participants}

The average age of the participants was $46.00 \pm 8.49$ years $(95 \%$ $\mathrm{CI}=44.2,47.7)$. The mean duration of their work experience was $5.20 \pm 2.65$ years $(95 \% \mathrm{CI}=4.7,5.8)$. There were about the same number of men and women. All the participants had completed at least primary school education (Table 1 ).

\subsection{Actual and perceived risk of acquiring hepatitis B infection among the participants}

The participants were required to give an assessment of their perceived risk of acquiring hepatitis B infection. The participants regarded themselves as having low (13.5\%), medium (13.5\%) and high-risk (21.3\%) of acquiring hepatitis B infection respectively. The remaining 46 (51.7\%) participants responded that they were unable 
Table 1

Socio demographic characteristics of the Cleaners at Babcock University Teaching Hospital, June 2016.

\begin{tabular}{|c|c|c|}
\hline Variable & Frequent & Percent \\
\hline \multicolumn{3}{|l|}{ Age (in years) } \\
\hline $25-34$ & 9 & 10.1 \\
\hline $35-44$ & 28 & 31.5 \\
\hline $45-54$ & 33 & 37.1 \\
\hline $55-64$ & 19 & 21.3 \\
\hline \multicolumn{3}{|l|}{ Sex } \\
\hline Male & 44 & 49.4 \\
\hline Female & 45 & 50.6 \\
\hline \multicolumn{3}{|l|}{ Religion } \\
\hline Christianity & 57 & 64 \\
\hline Islam & 30 & 33.7 \\
\hline Others & 2 & 2.2 \\
\hline \multicolumn{3}{|l|}{ Ethnicity } \\
\hline Igbo & 46 & 51.7 \\
\hline Yoruba & 35 & 39.3 \\
\hline Hausa & 8 & 9 \\
\hline \multicolumn{3}{|l|}{ Others } \\
\hline \multicolumn{3}{|c|}{ Highest level of education completed } \\
\hline Primary & 24 & 27 \\
\hline Secondary & 48 & 53.9 \\
\hline Tertiary & 17 & 19.1 \\
\hline \multicolumn{3}{|c|}{ Years of working experience } \\
\hline $1-3$ years & 32 & 36 \\
\hline $4-6$ years & 27 & 30.3 \\
\hline 7-9 years & 27 & 30.3 \\
\hline 10 or more years & 3 & 3.4 \\
\hline
\end{tabular}

to assess their risk of acquiring hepatitis B infection. Their actual risk of acquiring hepatitis B infection was also assessed by asking questions about previous occupational and non-occupational exposures. Exposure to occupational and non-occupational risks factors for hepatitis B infection is prevalent among the participants (Table 2).

An assessment of the actual risk of acquiring hepatitis $B$ infection showed that 34 (38.2\%), 39 (43.8\%), and $16(18.0 \%)$ had low, moderate, and high-risk respectively. No statistically significant association was found between the participants' actual and perceived risk of acquiring hepatitis $B$ infection $\left(\chi^{2}=2.413, \mathrm{df}=6\right.$, $\mathrm{p}=0.878$ )

\subsection{Knowledge of the participants about hepatitis B infection}

Fifty-eight (65.2\%) of the participants were aware of hepatitis B infection while thirty-one (34.8\%) had not heard of hepatitis B infection before.

The participants were required to respond to 26 questions about hepatitis B infection. The questions were in four domains, namely; routes of transmission (6 items), at-risk-groups (7 items), modes of prevention ( 6 items), and general questions ( 7 items). The mean hepatitis B infection knowledge score was $4.24 \pm 3.69$. The highest and lowest scores were 12 and 0 respectively. Eighty (89.9\%) of the participants had poor knowledge about hepatitis B infection while the remaining nine (10.1\%) had fair knowledge. None of the participants had good knowledge about hepatitis B infection. More than $50 \%$ of the participants gave the response 'I don't know' to all of the items across all the four domains. Misconceptions about all the four knowledge domains of hepatitis $B$ infection also exist among significant proportions of the participants (Table 3 ).

\subsection{Knowledge of the participants about hepatitis B vaccine}

The participants were required to respond to 13 questions about hepatitis B vaccine. The mean hepatitis B vaccine knowledge score was $1.06 \pm 1.75$. The highest and lowest scores were 8 and 2 respectively. Eighty-three $(93.3 \%)$ of the participants had poor knowledge about hepatitis B vaccine while the five (5.6\%) had fair knowledge. Only one (1.1\%) of the participants had good knowledge about hepatitis B vaccine. More than $60 \%$ of the participants gave the response 'I don't know' to all the 13 questions that were used to assess the knowledge about hepatitis B vaccine. Misconceptions about hepatitis B vaccine were also noted among the participants (Table 4 ).

\subsection{Hepatitis B screening and vaccination status of the participants}

Twenty-five (28.1\%) of the participants have ever had hepatitis B screening while 64 (71.9\%) had never been screened for hepatitis B before. Seventy-two (80.9\%) of the participants were not aware of their 'current' hepatitis B status. Fourteen (15.7\%) of the 17 participants who were aware of their 'current' status were negative while three (3.4\%) were positive for HBsAg. Two of three who claimed to be positive for hepatitis B said they completed the full course of treatment while the remaining one had no treatment at all.

All the participants responded that they were not vaccinated at the time of the study. The main reasons they gave for not being vaccinated were the lack of awareness (69.7\%), inaccessibility of vaccine $(23.6 \%)$, and cost $(6.7 \%)$.

\subsection{Perceived challenges to the implementation of hepatitis B infection control program among the participants}

The participants identified the possible barriers to the successful implementation of hepatitis B infection control program to include; low-risk perception among health workers, the poor orientation of new workers, lack of or poor knowledge, and the poor implementation of hospital policies (Table 5).

Table 2

Hepatitis B infection risk (occupational and non-occupational) among the Cleaners at Babcock University Teaching Hospital, June 2016.

\begin{tabular}{|c|c|c|}
\hline Variable & Yes $(\%)$ & No (\%) \\
\hline Have you ever been transfused with blood or blood products? & $37(41.6)$ & $52(58.4)$ \\
\hline Have you ever had surgery done? & $21(23.6)$ & $68(76.4)$ \\
\hline Do you use of gloves every time you carry out a procedure involving body fluids & $17(19.1)$ & $72(80.9)$ \\
\hline Have you had a needle stick injury in the last one year? & $24(27.0)$ & $65(73.0)$ \\
\hline Have you had any cut injury in the last one year? & $28(31.5)$ & $61(68.5)$ \\
\hline Have you ever had exposure to blood or body fluids on your mucous membrane in the last one year? & $30(33.7)$ & $59(66.3)$ \\
\hline Do you have any body scarification? & $41(46.1)$ & $48(53.9)$ \\
\hline Have you had any training on infection in the last one year? & $35(39.3)$ & $54(60.7)$ \\
\hline Have you ever had exposure to blood or body fluids on intact skin? & $57(64.0)$ & $32(36.0)$ \\
\hline Have you ever had splash of blood or body fluids to eye or mouth? & $9(10.1)$ & 80 (89.9) \\
\hline Have you ever had splash of blood on cuts or unprotected skin? & $18(20.2)$ & $71(79.8)$ \\
\hline
\end{tabular}


Table 3

Knowledge of hepatitis B infection among the Cleaners at Babcock University Teaching Hospital, June 2016.

\begin{tabular}{|c|c|c|c|}
\hline Variable & Correct $(\%)$ & Wrong (\%) & I don't know (\%) \\
\hline \multicolumn{4}{|l|}{ Routes of transmission } \\
\hline Sharps injury & $25(28.1)$ & $9(10.1)$ & $55(61.8)$ \\
\hline Blood donation from infected person & $13(14.6)$ & $14(15.7)$ & $62(69.7)$ \\
\hline Sexual intercourse with infected person & $12(13.5)$ & $15(16.9)$ & $62(69.7)$ \\
\hline From mother to child during pregnancy & $12(13.5)$ & $12(13.5)$ & $65(73.0)$ \\
\hline Faeco-oral & $11(12.4)$ & $8(9.0)$ & $70(78.7)$ \\
\hline Polluted water & $5(5.6)$ & $10(11.2)$ & $74(83.1)$ \\
\hline \multicolumn{4}{|l|}{ At risk groups } \\
\hline Commercial Sex Workers & $26(29.2)$ & $17(19.1)$ & $46(51.7)$ \\
\hline Men who sleep with men & $4(4.5)$ & $20(22.5)$ & $65(73.0)$ \\
\hline Individuals with multiple sexual partners & $7(7.9)$ & $16(18.0)$ & $66(74.2)$ \\
\hline Sickle cell disease patients & $7(7.9)$ & $24(27.0)$ & $58(65.2)$ \\
\hline Long distance drivers & $15(16.9)$ & $15(16.9)$ & $59(66.3)$ \\
\hline Health care workers & $9(10.1)$ & $18(20.2)$ & $62(69.7)$ \\
\hline Injection drug users & $14(15.7)$ & $20(22.5)$ & $55(61.8)$ \\
\hline \multicolumn{4}{|l|}{ Modes of prevention } \\
\hline Vaccination & $23(25.8)$ & $11(12.4)$ & $55(61.8)$ \\
\hline Proper disposal of sharps & $8(9.0)$ & $19(21.3)$ & $62(69.7)$ \\
\hline Avoiding multiple sexual partner & $11(12.4)$ & $13(14.6)$ & $65(73.0)$ \\
\hline Avoiding drinking contaminated water & $20(22.5)$ & $6(6.7)$ & $63(70.8)$ \\
\hline Avoiding uncooked food & $18(20.2)$ & $6(6.7)$ & $65(73.0)$ \\
\hline Consistent and appropriate use of gloves & $7(7.9)$ & $13(14.6)$ & $69(77.5)$ \\
\hline \multicolumn{4}{|l|}{ Others } \\
\hline Hepatitis B infected person may be asymptomatic for long time & $10(11.2)$ & $23(25.8)$ & $56(62.9)$ \\
\hline Every person exposed to hepatitis B virus will develop acute hepatitis immediately & $29(32.6)$ & $10(11.2)$ & $50(56.2)$ \\
\hline Hepatitis B virus is highly infectious & $24(27.0)$ & $17(19.1)$ & $48(53.9)$ \\
\hline Only small proportion of the world population is infected with hepatitis B virus & $18(20.2)$ & $15(16.9)$ & $56(62.9)$ \\
\hline Hepatitis B virus mainly affects liver & $19(21.3)$ & $13(14.6)$ & $57(64.0)$ \\
\hline Hepatitis B is more infectious than HIV & $15(16.9)$ & $17(19.1)$ & $57(64.0)$ \\
\hline Hepatitis B infection is more common in Sub Saharan Africa & $15(16.9)$ & $14(15.7)$ & $60(67.4)$ \\
\hline
\end{tabular}

Table 4

Knowledge of hepatitis B vaccine among the Cleaners at Babcock University Teaching Hospital, June 2016.

\begin{tabular}{|c|c|c|c|}
\hline Variable & $\begin{array}{l}\text { Correct } \\
(\%)\end{array}$ & $\begin{array}{l}\text { Wrong } \\
(\%)\end{array}$ & $\begin{array}{l}\text { I don't know } \\
(\%)\end{array}$ \\
\hline There is effective vaccine to prevent hepatitis B infection & $27(30.3)$ & $6(6.7)$ & $56(62.9)$ \\
\hline Hepatitis B vaccine can be given as post-exposure prophylaxis & $7(7.9)$ & $\begin{array}{l}15 \\
(16.9)\end{array}$ & $67(75.3)$ \\
\hline Hepatitis B vaccine is contra indicated for immune compromised patients & $7(7.9)$ & $8(9.0)$ & $74(83.1)$ \\
\hline Hepatitis B vaccine is effective to treat patients with acute hepatitis B infection & $6(6.7)$ & $5(5.6)$ & $78(87.6)$ \\
\hline Hepatitis B vaccine is highly effective in preventing hepatitis B infection if given within 48 hours after exposure & $6(6.7)$ & $3(3.4)$ & $80(89.9)$ \\
\hline Hepatitis B vaccine should be given to health care workers as part of work place safety & $5(5.6)$ & $5(5.6)$ & $79(88.8)$ \\
\hline $\begin{array}{l}\text { Full course of hepatitis B vaccine may give lifelong immunity but for Health professionals, one further booster after } 5 \text { years of the first } \\
\text { dose is recommended }\end{array}$ & $6(6.7)$ & $5(5.6)$ & $78(87.6)$ \\
\hline After taking full dose vaccination of hepatitis $\mathrm{B}$, there is no need for a blood test to confirm immunity against hepatitis $\mathrm{B}$ & $7(7.9)$ & $3(3.4)$ & $79(88.8)$ \\
\hline Full dose hepatitis B vaccine provides $100 \%$ protection for $90 \%$ of adults & $3(3.4)$ & $7(7.9)$ & $79(88.8)$ \\
\hline Full dose hepatitis B vaccine protects against HBV for at least 15 years & $4(4.5)$ & $6(6.7)$ & $79(88.8)$ \\
\hline Hepatitis B vaccine causes problems if given to people who are already immune & $5(5.6)$ & $2(2.2)$ & $82(92.1)$ \\
\hline Hepatitis B vaccine is recommended for all health care workers & $5(5.6)$ & $5(5.6)$ & $79(88.8)$ \\
\hline One or two does of hepatitis B vaccine are sufficient to be fully immunized for an adult & $6(6.7)$ & $7(7.9)$ & $76(85.4)$ \\
\hline
\end{tabular}

Table 5

Perceived challenges to the implementation of hepatitis B infection control program among the Cleaners at Babcock University Teaching Hospital, June 2016.

\begin{tabular}{lll}
\hline Variable & Yes (\%) & No (\%) \\
\hline Inexistent hospital policy & $36(40.4)$ & $53(59.6)$ \\
Poor orientation of new health workers & $46(51.7)$ & $43(48.3)$ \\
Low risk perception among workers & $54(60.7)$ & $35(39.3)$ \\
Poor implementation of hospital policy & $40(44.9)$ & $49(55.1)$ \\
Poor knowledge & $42(47.2)$ & $47(52.8)$ \\
Fear of side effects of vaccine/injection & $37(41.6)$ & $52(58.4)$ \\
\hline
\end{tabular}

\section{Discussion}

Occupational exposure to blood, blood products, and other body fluids places health care workers at an additional risk of contracting hepatitis B infection over people in the general population. ${ }^{1}$ The high response rate that was noted in this study may underscore an interest in hepatitis B infection among the participants. The Cleaners have both occupational and nonoccupational exposure to the risk factors for hepatitis B infection. Most of them have low to moderate risk of acquiring hepatitis $B$ infection although a significant proportion has a high-risk of 
acquiring the infection. In contrast, most of the cleaners had no or poor risk perception of contracting hepatitis $\mathrm{B}$ infection. The perception of the risk of contracting hepatitis $B$ infection is quite low when compared with other health care workers. ${ }^{17,18}$ Ibekwe and Ibeziako ${ }^{17}$ have also found statistically significant difference in the risk perception for hepatitis B infection among ward attendants and other health workers in a tertiary hospital in eastern Nigeria. This difference may be because cleaners tend to be less educated, have little or no medical training, and often have their specific training needs overlooked within the healthcare setting. ${ }^{16}$ Poor risk perception in the presence of significant levels of actual risk of contracting hepatitis B infection may actually lead to an increased risk. This is because the participants are unable to appreciate the dangers that they are exposed to and as such, are less likely to take necessary precautions. This is the case among the participants in this study among whom only $19.1 \%$ use gloves every time they carry out a procedure involving body fluids.

About $90 \%$ of the participant had poor knowledge about hepatitis B with a mean score of 4.24 out of the maximum possible score of 26 . More than $50 \%$ of the participants had no knowledge of hepatitis B while misconceptions were highly prevalent. Other studies among the general population of health workers and those among doctors and nurses have shown much higher levels of knowledge and significantly lower levels of misconceptions about hepatitis B infection. ${ }^{19-21}$ This difference suggests that cleaners may differ significantly from other health workers in their knowledge about hepatitis B infection. Health workers may not be a homogenous group as it relates to their knowledge about hepatitis B infection. This is probably one of the first times that the risk and knowledge of hospital cleaners about hepatitis B infection have been described. It is important for future studies to differentiate between the roles of clinical and nonclinical health workers as it relates to the risk of hepatitis $B$ infection. Interventions aimed at the control of hepatitis B infection in health care settings through the improvement of knowledge of health workers may need to be structured to address the specific needs of the various categories of health workers separately. Knowledge gaps exist across all the four hepatitis B knowledge domains (routes of transmission, at-risk-groups, modes of prevention, and general questions) that were assessed. In fact, more than a third of the participants were not aware of hepatitis B infection. There is, therefore, an urgent need for training for the cleaners on the transmission, risk, prevention and sundry issues as it relates to hepatitis $\mathrm{B}$ infection.

The participants' awareness and knowledge about hepatitis B vaccine were also poor. This may be related to poor knowledge about hepatitis $\mathrm{B}$ infection. The knowledge about the vaccine is poorer and associated with more misconceptions that the knowledge about the infection. The cleaners have poorer knowledge about the vaccine when compared with findings among general and other categories of health workers. ${ }^{11,18}$ The levels of awareness of hepatitis B infection and its vaccine have been observed to be generally lower than that of HIV in spite of it being more infectious than HIV. ${ }^{22}$ The unusually low levels of awareness and knowledge about hepatitis B vaccine, a potent vaccine that has been around since 1981, calls for prompt action among this group of hospital staff.

None of the participants reported having received hepatitis B vaccination. Studies have reported poor levels of vaccination among health workers ${ }^{11,13-15}$ but even at that, a zero vaccination level is unacceptable. This is particularly poor considering the risk of occupational exposure that is prevalent in health workers including cleaners. However, this may be explained by the low level of awareness and poor knowledge of the infection and vaccine that is prevalent among the participants. Although some of the participants suggested that accessibility was a barrier to their receiving the vaccine, hepatitis $B$ is widely available in Nigeria. The vaccine is available for free as part of the National Programme on Immunization (NPI) for children less than one year both in the monovalent form and as part of the pentavalent vaccine. ${ }^{23,24}$ It is also available for adults but at a cost. It is most likely that lack of awareness/poor knowledge about HBV and cost are the major barriers.

Participants in this study identified the possible challenges to a successful implementation of hepatitis B control in health care settings. The identified challenges are similar to those identified by other studies among the general and specified populations of health workers. ${ }^{18}$ Most of the participants listed inexistence of hospital policy as a barrier. However, the hospital has an operational infection control policy with a duly constituted infection committee. This may suggested that the policy is not well-disseminated and that the committee needs to device appropriate strategies to disseminate the policy to different cadres of health workers.

However, the findings of this study should be interpreted with some caution. The data that was collected is subject to recall bias. Besides, the single-site study provides some challenges for external validity. However, the study provides useful insight to the possible peculiarity of nonclinical health workers which could be used as basis for future larger studies. It provides a basis of focus both for research and policy for the inclusion hospital cleaners in hepatitis B infection control among health workers.

\section{Conclusions}

Health workers, including cleaners, are at an increased risk of hepatitis $B$ infection compared to the general population because of occupational exposure to body fluids. Hospital cleaners have poor risk perception, low awareness, and knowledge about hepatitis B infection. They have poor knowledge and uptake of hepatitis $B$ vaccine. A lot of misconceptions and gaps also exist in their knowledge. Their knowledge about hepatitis $B$ vaccine and infection is poorer than that of the general population of health workers and some specific health professionals including Doctors and Nurses. It is likely that health workers differ in what they know about hepatitis B infection and vaccine. This may be due to the differences in the levels of education, training, and perceived relevance within hospital settings. This study underscores the weakness that is inherent in approaching hospital staff as a homogenous unit as it relates to hepatitis B control. Hospital cleaners have an urgent need for training on the transmission, risk, prevention and sundry issues as it relates to hepatitis B infection and vaccine. In order to achieve effective control of hepatitis $B$ infection in health care settings, hospital administrations should pay attention to staff training and retraining with particular attention being paid to categories of workers who may easily be overlooked.

\section{Competing interests}

The authors declare that they have no competing interests.

\section{Funding}

This research did not receive any specific grant from funding agencies in the public, commercial, or not-for-profit sectors.

\section{Authors' contributions}

OA, OS, CE and DO conceived the study and conducted the literature search. OA designed the study and wrote the first draft of the manuscript. AO, BM, and AA participated equally in data 
collection and analysis. All the authors reviewed and approved the final draft of the manuscript.

\section{Ethics approval and consent to participate}

This study was approved by the Babcock University Human Research Ethics Committee (BUHREC/005/17). All participants were required to sign an informed consent form that also covered for HBV sample analysis. Each participant received a unique identification code. The personal identification details of participants were not required at any stage during the study. The study supervisors made sure that privacy and confidentiality were maintained all through the period of the study. The supervisors gave each participant an educational material on hepatitis $B$ infection and vaccine after completion of the questionnaire. Eligible participants were referred to the Community Medicine Department clinic to access hepatitis B vaccine which was made available to them for free. Those who gave consent to receive the vaccine were given 3 doses of hepatitis B vaccine (at first contact, at one month and at two months) by qualified health workers in the Department. They were educated on the common side effects of the vaccine and encouraged to immediately present back at the clinic in case they noticed any of those symptoms. Hepatitis B positive participants were referred for specialist care.

The dataset supporting the conclusions of this article is available from the corresponding author on reasonable request.

\section{Acknowledgements}

The authors would like to acknowledge the contributions of Dr. Temitope Ashipa and Mrs. Basirat Okuboyejo to the success of the study. The Nigerian National Petroleum Corporation provided hepatitis B vaccine to all eligible study participants. The authors are very grateful to the research assistants and study participants.

\section{References}

1. WHO. Hepatitis B. [http://www.who.int/mediacentre/factsheets/fs204/en/. Accessed 22 February 2017].

2. Logano R, Naghavi M, Foreman K, et al. Global and regional mortality from 235 causes of death for 20 age groups in 1990 and 2010: a systematic analysis for the Global Burden of Disease Study 2010. Lancet. 2012;380(9859):2095212810.1016/S0140-6736(12)61728-0.

3. Ola S, Otegbayo J, Odaibo G, Olaleye O, Olubuyide O. Serum Hepatitis C virus and hepatitis B surface antigenaemia in Nigerian patients with acute Icteric hepatitis. West Afr J Med. 2002;21(3):15-17.

4. Emechebe G, Emodi I, Ikefuna A, et al. Hepatitis B virus infection in Nigeria - a review. Niger Med J. 2009;50(1):18-22.

5. Mast E, Weinbaum C, Fiore A, et al. A comprehensive immunization strategy to eliminate transmission of hepatitis B virus infection in the United States recommendations of the Advisory Committee on Immunization Practices
(ACIP) part II: immunization of adults. Morb Mortal Wkly Rep. 2006;55(R16):125.

6. Bada A, Olatunji P, Adewuyi J, Iseniyi J, Onile B. Hepatitis B surface antigenaemia in Ilorin, Kwara State, Nigeria. Cent Afr J Med. 1996;42 (5):139-141.

7. Sadoh A, Sadoh W. Serological markers of hepatitis B infection in infants presenting for their first immunization. Niger J Paediatr. 2013;40(3):24825310.4314/njp.v40i3,9.

8. Belo A. Prevalence of Hepatitis B virus markers in surgeons in Lagos, Nigeria. East Afr Med J. 2000;77(5):283-285.

9. Lesi O, Kehinde M, Omilabu S. Prevalence of the hepatitis B "e" antigen in Nigerian patients with chronic liver disease. NOJHM. 2004;14(1):1-4.

10. Musa B, Samaila A, Femi O, Borodo M, Bussell S. Prevalence of hepatitis B virus infection in Nigeria, 2000-2013: a systematic review and meta-analysis. Niger J Clin Pract. 2015;18(2):16310.4103/1119-3077.151035.

11. Abeje GAzage M. Hepatitis B vaccine knowledge and vaccination status among health care workers of Bahir Dar City Administration, Northwest Ethiopia: a cross-sectional study. BMC Infect Dis. 2015;15(1)10.1186/s12879-015-0756-8.

12. Bakry S, Mustafa A, Eldalo A, Yousif M. Knowledge, attitude, and practice of healthcare workers toward hepatitis B virus infection in Sudan. Int J Risk Saf Med. 2012;24(2):95-10210.3233/JRS-2012-0558.

13. Djeriri K, Laurichesse H, Merle J, et al. Hepatitis B in Moroccan health care workers. Occup Med (London). 2008;58(6):419-42410.1093/occmed/kqn071.

14. Khan N, Ahmed S, Khalid M, Siddiqui S, Merchant A. Effect of gender and age on the knowledge, attitude and practice regarding Hepatitis B and C and vaccination status of Hepatitis B among medical students of Karachi Pakistan. J Pak Med Assoc. 2010;60(6):450-455.

15. Burnett R, Francois G, Mphahlele M, et al. Hepatitis B vaccination coverage in healthcare workers in gauteng province, South Africa. Vaccine. 2011;29 (25):4293-429710.1016/j.vaccine.2011.03.001.

16. Gorar Z, Butt Z, Aziz I. Risk factors for bloodborne viral hepatitis in healthcare workers of Pakistan: a population based case-control study. BMJ Open. 2014;4 (7):e00476710.1136/bmjopen-2013-004767.

17. Ibekwe RIbeziako N. Hepatitis B vaccination status among health workers in Enugu, Nigeria. Niger J Clin Pract. 2006;9(1):7-10.

18. Adekanle O, Ndububa D, Olowookere S, Ijarotimi O, Ijadunola K. Knowledge of hepatitis B virus infection, immunization with hepatitis B vaccine, risk perception, and challenges to control hepatitis among hospital workers in a Nigerian tertiary hospital. Hepat Res Treat. 2015;2015:1-610.1155/2015/ 439867.

19. Abiola A, Agunbiade A, Badmos K, Lesi A, Lawal A, Alli Q. Prevalence of HBsAg, knowledge, and vaccination practice against viral hepatitis B infection among doctors and nurses in a secondary health care facility in Lagos state, Southwestern Nigeria. Pan Afr Med J. 2016;23:16010.11604/pamj.2016.23.160.8710.

20. Hassan M, Awosan K, Nasir S, et al. Knowledge, risk perception and hepatitis B vaccination status of healthcare workers in Usmanu Danfodiyo University Teaching Hospital, Sokoto Nigeria. J Public Health Epidemiol. 2016;8(4):535910.5897/JPHE2015.0795.

21. Fufore M, Cook P, Kirfi A. Health workers' knowledge, attitude, and practice towards hepatitis B infection in Northern Nigeria. Int J Caring Sci. 2016;9 (3):955-965.

22. Frambo A, Atashili J, Fon P, Ndumbe P. Prevalence of HBsAg and knowledge about hepatitis B in pregnancy in the Buea Health District, Cameroon: a crosssectional study. BMC Res Notes. 2014;7(1):39410.1186/1756-0500-7-394.

23. Nigeria Launches Penta Vaccine. [http://www.afro.who.int/en/nigeria/pressmaterials/item/4735-nigeria-launches-penta-vaccine.html. Accessed 22 February 2017].

24. Ikobah J, Okpara H, Elemi I, Ogarepe Y, Udoh E, Ekanem E. The prevalence of hepatitis B virus infection in Nigerian children prior to vaccine introduction into the national programme on immunization schedule. Pan Afr Med J. 2016;23:12810.11604/pamj.2016.23.128.8756. 